adrenergic casualty department, where further delays would take place and possibly further errors by inexperienced junior staff. Unfortunately, the message of the British Heart Foundation report is deeply ambivalent, doubtless reflecting a "dissensus" in the group. The overall result, however, will be to discourage general practitioners from participating fully and exploiting the major benefits that thrombolytic treatment can confer. Rather than "contracting out," as the report suggests, I hope that general practitioners will insist on local schemes to bolster their confidence in the full early management of myocardial infarction.

G H HAI.I.

Exeter EX2 4NT

1 Hall GH. Bolus streptokinase after myocardial infarction. Luncet 1987; ;i: $96-87$.

2 British Heart Foundation Working (iroup. Role of the genera practitioners in managing patients with myocardial infarction: impact of thrombolytic treatment. Br.Med $\mathcal{J}$ 1989:299:555-6 (26 August.

\section{Child sexual abuse}

SIR, - I am pleased that investigations for sexually transmitted diseases including screening tests for gonorrhoea and HIV infection should be done on sexually abused children. ${ }^{\prime}$

Over two years five children (two girls, three boys) aged $4-71 / 2$ years presented at this teaching hospital, not with a history of sexual abuse but with urethral or vaginal discharge proved to be due to Neisseria gonorrhoea. One 5 year old girl subsequently admitted to sexual abuse by a 10 year old boy at school. The boy refused to be investigated by us. The other girl, aged $71 / 2$ years, denied sexual abuse and had an intact hymen. Three bovs were subsequently found to have contracted the disease through a parent or older member of the family.

Reports on sexual abuse in children in the developing countries are rare, ' but our experience shows that doctors and, in particular, paediatricians in these countries need to be aware of sexual abuse and that the campaign against HIV infection and other sexually transmitted diseases for at risk subjects should include children who have been sexually abused.

Department of Paediatrics,

FELICIA EKE

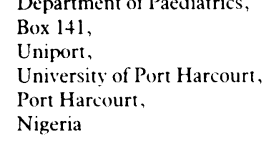

1 Bamford F, Roberts R. Child sexual abuse-II. Br .Hed 1989:299:377-82. 5 Auguse)

2 Ogunbanjo BO. Sexually transmitted diseases in Nigeria. A review of the present situation. West African fournal of Medicine 1989;8:+2-9.

\section{Marker for alcohol abuse}

SIR, - The prospect of a more reliable marker for alcoholism as described by $\mathrm{Mr} \mathrm{A}$ Kapur and colleagues is most welcome.' Unfortunately, however, their last paragraph states that "the cost of the test compares favourably with that of other standard laboratory investigations." The given method does not specify the reagents closely enough for the costs of consumables to be worked out, but I challenge Mr Kapur and colleagues to produce a result for 22 p per specimen (the current cost of consumables for a $\gamma$-glutamyltransferase estimation in this department). A full blood count (including mean corpuscular volume) performed by our haematology department represents even better value at $11 \mathrm{p}$ for consumables. The isolation and identification of carbohydrate deficient transferrin is patently more labour intensive than either of the above automated methods, and the rather glib dismissal of necessary technician time shows laboratories that will be asked to perform these investigations on a day to day basis, given the current volume of requests for markers of alcohol abuse.

Chemical pathology departments that seek to sell this "fairly simple, sensitive, and inexpensive" technique to their managers and clinicians as an alternative to cheaper current tests (albeit with known limitations) may thus be hoist with their own petard.

\section{Chemical Pathology Department,}

Trathord Genal Hospial

1 Kapur $A$, Wild $G$, Milford-Ward A, Triger DR. Carbohydrate
deficient transferrin: a marker for alcohol abuse. Br. Med 7 1989:299:427-31.112 August.

\section{Passive smoking and cardiorespiratory health in Scotland}

SIR, - Mr David J Hole and colleagues,' when discussing results from their prospective study, state that studies of cotinine in passive smokers suggest that the dose received may be "equivalent to smoking up to three cigarettes a day." To support this misleading statement they cite a solitary study in Japan, ${ }^{2}$ in which urinary cotinine concentrations in non-smokers averaged $8 \%$ of those in smokers. This contrasts sharply with evidence from Western populations, ${ }^{3}$ which indicates that average cotinine concentrations in non-smokers exposed to environmental tobacco smoke are about $0.7 \%$ of those in smokers. ${ }^{+}$Blot and Fraumeni speculated that Japanese people might have especially heavy exposure to environmental tobacco smoke. Other studies in Japan" (and abstracts presented by S Umemura and colleagues and E Higashi and colleagues, international conference on indoor air quality, Tokyo, 1987) have, however, sustained earlier suspicions that the methodology used in the original study was faulty. When estimating passive exposure relative to that from active smoking nicotine based indices are of dubious value, partly because that in mainstream smoke, is largely in the vapour phase and need not be absorbed by the lungs. Based on measurements of retained particulate matter, exposure to environmental tobacco smoke averages at about $0.05 \%$ of the exposure of a person who smokes 20 cigarettes each day ${ }^{4}$-that is 0.01 cigarettes a dav.

That such minute doses should elicit observable health effects is surprising, and epidemiologica studies that report associations with exposure to environmental tobacco smoke have been critically examined for possible bias. One important bias arises because some smokers deny present or pas smoking. Mr Hole and colleagues refer to one of my papers, ${ }^{,}$but infortunately have totally misunderstood how such bias arises. They state that differential rates of misclassification imply that someone in their "double smoking group" has to be "more likely to pretend to be a non-smoker than a lack of understanding for the problems of nicotine in environmental tobacco smoke, unlike

someone in the single smoking group." This is untrue because it overlooks the fact that smokers tend to cohabit with smokers.

The table shows how differential misclassification can arise, assuming $2 \%$ of the index subjects had denied smoking. The higher proportion of smokers $(15.6 \%)$ in the observed passive smoking group compared with the observed control group $(6.8 \%)$ would cause substantial bias for an end point strongly related to active smoking. Thus if risk were increased 20 times in smokers, and not by exposure to environmental tobacco smoke, the relative risks observed would be 6.90 for active smoking and 1.74 for passive smoking, not 20 and 1 respectively. Many studies have shown higher rates of denial of smoking than assumed in the table, "' so this source of bias is evidently important. It can explain the many positive associations reported in the Scottish study, 'most of which were not statistically significant.

The results for lung cancer from the Scottish study were based on only nine deaths among self reported non-smokers. This contrasts with over 2000 deaths in other published studies. Clearly, the new data contribute little to the overall picture. Evidence on environmental tobacco smoke and heart disease has previously been reviewed and considered inconclusive. "Although the Scottish study reported more deaths from heart disease than from lung cancer, it should not materially affect this view.

P N Lee Statistics and Computing,

PETER N I.EF

Sutton. Surrey SM2 5DA

1 Hole DJ, Gillis CR, Chopra C, Hawthorne VM. Passive smoking and cardiorespiratory health in a general population in the west of Scotland. Br. Med $\mathcal{f}$ 1989;299:423-7. (12 August.

2 Matsukura S, Taminato T, Kitano N, et al. Effects of environmental tobacco smoke on urinary cotinine excretion in nonsmokers. N Engl J.Med 1984;311:828-32.

3 US Department of Health and Human Services. The health consequences of involuntary smoking. A report of the surgeon general. Rockville, Maryland: Public Health Service, Office on Smoking and Health, 1986:105-8.

4 Lec PN. An alternative explanation for the increased risk of lung con PW, eds. Indor and ambien air unalin. Londy R, Kirk PW, eds. Indoor and ambient air quality. London: Selper,

Blot WJ, Fraumeni J. Passive smoking and lung cancer. fournal of the National Cancer Institute 1986;77:993-9.

6 Muramatsu M, Umemura S, Okada T, Tomita H. Estimation of personal exposure to tobacco smoke with a newly developed nicotine personal monitor. Environ Res 1984:35:218-27.

7 Adlkofer F, Scherer G, Heller W-D. Passive smoking. N Engl f Med 1985;312:719-20.

8 Robins J. Appendix I). Environmental tobacco smoke. Measuring exposure and assessing health effects. Washington: National Academy Press, 1986:294-337.

9 Lee PN. Misclassification as a factor in passive smoking risk. Lancet 1986;ii:867.

10 Lee PN. Misclassification of smoking habits and passize' smoking. A review of the evidence. Berlin: Springer-Verlag, 1988

11 National Research Council. Environmental tobacco smoke. Measuring exposure and assessing health effects. Washington: National Academy Press, 1986:257-68.

\section{Donating drugs to the Third World}

SIR,-As director of Intercare, the organisation approved by the BMA Board of Science and Education for promoting the salvaging of suitable medical samples for use in the Third World, I am happy to answer the criticisms expressed by $\mathrm{Dr}$ Frances Griffiths.'

Differential misclassification caused by $2 \%$ of index subjects denying smoking regardless of cohabitee's smoking habits

\begin{tabular}{|c|c|c|c|c|c|c|}
\hline Exposure group ${ }^{\star}$ & $\begin{array}{l}\text { Smoking state } \\
\text { of index subject }\end{array}$ & $\begin{array}{l}\text { Smoking state } \\
\text { of cohabitee }\end{array}$ & $\begin{array}{c}\text { "True" } \\
\text { distribution }\end{array}$ & $\begin{array}{c}\text { Effects of } \\
\text { denial }\end{array}$ & $\begin{array}{c}\text { Observed } \\
\text { distribution } \dagger\end{array}$ & $\begin{array}{l}\text { Percentage } \\
\text { who have } \\
\text { smokedf }\end{array}$ \\
\hline Controls & Non-smoker & Non-smoker & 399 & +29 & 428 & $6 \cdot 8$ \\
\hline Passive smokers & Non-smoker & Smoker & 205 & +38 & 243 & $15 \cdot 6$ \\
\hline Single smokers & Smoker & Non-smoker & 1449 & -29 & 1420 & \\
\hline Double smokers & Smoker & Smoker & 1907 & -38 & 1869 & \\
\hline
\end{tabular}

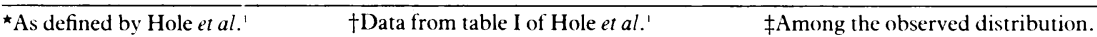

